\title{
Plasma lipids and atherosclerosis
}

\author{
LARS A. CARLSON \\ From the Department of Geriatrics, University of Uppsala, Uppsala, Sweden
}

Hyperlipidaemia may be defined as the presence of excess lipid in the blood. It may be classified according to the nature of the lipids which are increased. A classification of hyperlipidaemia based on the fasting levels of cholesterol and triglyceride allows of three possible abnormal groups, which are shown in table I together with the corresponding classification according to Fredrickson as modified in the World Health Organization Memorandum (1970). The Fredrickson system is based on lipoprotein analyses and has six classes compared

\begin{tabular}{lllll}
\hline & \multicolumn{3}{l}{ Plasma Lipid Group } \\
\cline { 2 - 5 } & $A$ & $B$ & $C$ & $D$ \\
\hline Cholesterol & Normal & High & Normal & High \\
Triglyceride & Normal & Normal & High & High \\
Fredrickson type & - & IIA & IV (I) & IIB, III, IV, \\
& & & & V (I) \\
\hline
\end{tabular}

Table I Classification of hyperlipidaemia based on fasting plasma cholesterol and triglyceride with the three-B, C, and D-of the classification based on plasma cholesterol and triglyceride levels (table I). Groups B and C correspond to definitive Fredrickson types, IIA and IV respectively, while group D, with a combined increase of cholesterol and triglyceride, may contain all the different Fredrickson types except IIA.

However, although the classification systems appear straightforward, whether based on plasma lipids or on plasma lipoproteins, a major problem is to define what is abnormal, as the 'normal range' depends upon the way in which the normal population is selected. This is illustrated by our study of 151 males, aged 26 to 73 years, randomly selected from Stockholm (Carlson, 1960a). On examination in 1954 they were declared healthy, and remained in good health until they were re-examined five years later. This whole sample (group 1, see fig. 1) could very well be accepted as a 'normal' control group, but 30 subjects were excluded on the basis of the clinical history and examination in 1959, leaving 121 (group 2). A further group of 19 was then excluded

Normal men $41-73$ years.
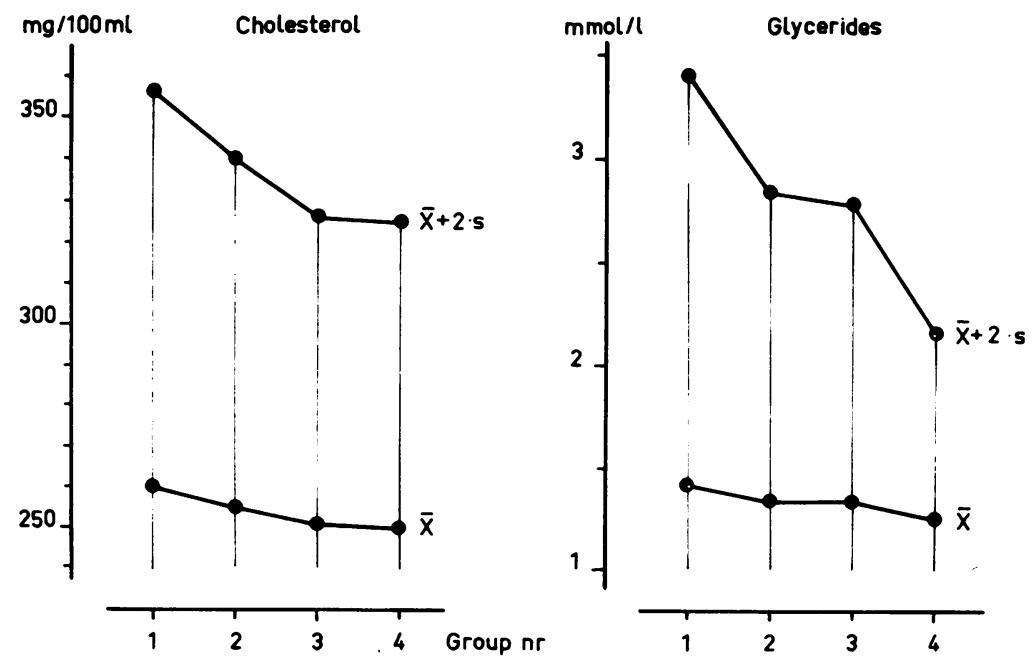

Fig. 1 Effect of the method of selection of control subjects on the normal range given by the mean $(\bar{x})+2$ standard deviations. Groups 2-4 are formed by eliminating different subjects from the initial sample (group 1). For explanation see text. 
because of a family history of ischaemic heart disease or cerebral vascular disease, leaving 102 (group 3). Finally a further group was excluded on the basis of an abnormal ECG after exercise, leaving 78 (group 4). Figure 1 shows the effect of this selection procedure on the mean value and range for plasma cholesterol and triglyceride. There is little effect on the mean values but the upper limit calculated from 2 standard deviations falls significantly for both triglycerides and cholesterol for each of the clinical procedures leading to exclusion of subjects. This is of course due to the fact that the selection procedure eliminates subjects who, though apparently normal, are likely for the reasons given to have high values.

Normal lipoprotein levels may also be defined as the levels required to maintain health but this again is not very helpful when dealing with patients, because it is difficult to define 'health'. In 1960 we examined a group of males who had survived an episode of myocardial infarction, and found that in only $41 \%$ did the plasma triglyceride values fall within the normal range as defined for the final group of 78 (group 4) of the random sample described above; $59 \%$ of the coronary population therefore had hyperlipidaemia, $24 \%$ with type IIA (group B, and table I), $27 \%$ probably with type IV (group C), $8 \%$ in the mixed group (group D) (Carlson, 1960b).

It is well known that retrospective studies of survivors of myocardial infarction have limitations. Therefore the high percentage of patients with hypertriglyceridaemia falling in groups $C$ and $D$ led us to study prospectively the relationship of plasma cholesterol and triglyceride levels to the occurrence of ischaemic heart disease. In 1961/62 3168 male subjects aged 35-70 years attending a health control centre in Stockholm were examined, and fasting plasma triglyceride and cholesterol were estimated. By the time of the first follow up nine years later (Carlson and Böttiger, 1972) there had been 99 new episodes of ischaemic heart disease. Twenty-eight of these occurred in subjects who had, at the initial examination, revealed evidence of cardiovascular or ${ }^{-}$ other major disease. Therefore the number of $\overrightarrow{\vec{F}}$ incidents (table II) is shown both in relation to the total sample and to a 'true prospective group' formed by excluding from the total all subjects in whom there $\overline{\bar{s}}$.

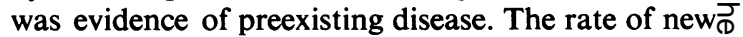
incidents increased linearly with concentration of both triglycerides and cholesterol (fig. 2). A mores detailed analysis of the rate of occurrence in men $\overrightarrow{0}$ aged 35-59 with different types of hyperlipidaemia is presented in table III. It is seen that the frequency $\vec{\omega}$ of new incidents increases from group $A$ to क्ते maximum in group D (type IIB) and depends more on triglyceride levels (high in C and D) than oncholesterol levels (high in B and D). Of course the plasma lipids are not the only important risk factors $\vec{i}$ for example, the rate of occurrence of ischaemic heart disease was greater in smokers than in non-? smokers (Carlson and Böttiger, 1972), and, as the total number of risk factors increases, so the risk increases progressively (fig. 3 ).

A third study is in progress in Stockholm where about 5000 subjects are screened annually at a health control station. Subjects with massive hyperlipidaemia, constituting $2-3 \%$ of the total, all in good health and in active work, are admitted to 20 special lipid clinic at the Karolinska Hospital and

\begin{tabular}{|c|c|c|c|c|c|}
\hline & \multicolumn{4}{|c|}{ Myocardial Infarction } & \multirow[t]{3}{*}{ Total } \\
\hline & \multicolumn{2}{|c|}{ In Hospital } & \multicolumn{2}{|c|}{ Outside Hospital } & \\
\hline & Alive & Dead & $\begin{array}{l}\text { Sudden } \\
\text { Death }\end{array}$ & $\begin{array}{l}\text { Found } \\
\text { Dead }\end{array}$ & \\
\hline \multirow{2}{*}{$\begin{array}{l}\text { Total sample } \\
\text { 'True prospective } \\
\text { group' }\end{array}$} & 49 & 31 & 16 & 3 & 99 \\
\hline & 38 & 17 & 13 & 3 & 71 \\
\hline
\end{tabular}

Table II Number of cases of acute ischaemic heart disease in the Stockholm projective study of 3168 men

The 'true prospective group' refers to subjects without evidence of preexisting disease when first examined; 28 incidents occurred in subjects with preexisting disease, viz, 16 with cardiovascular disease seven with diabetes, and five with other major diseases. The firs $\$$ examination was in 1961 and the follow-up in 1970.

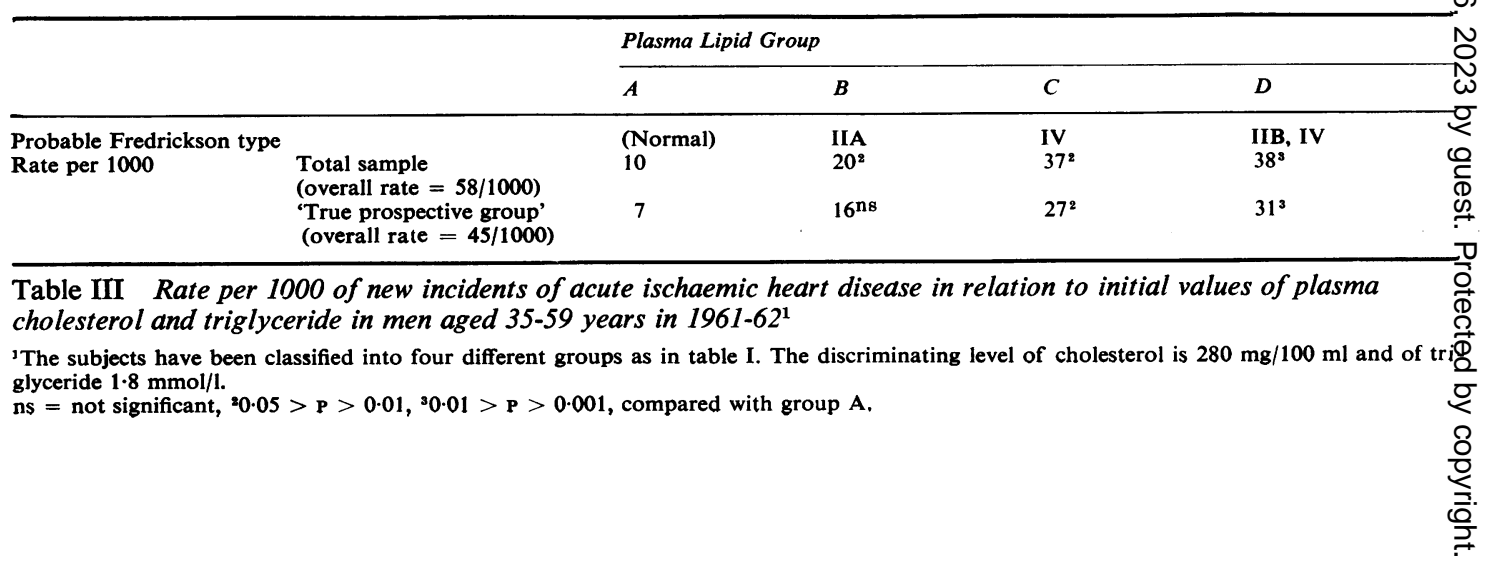



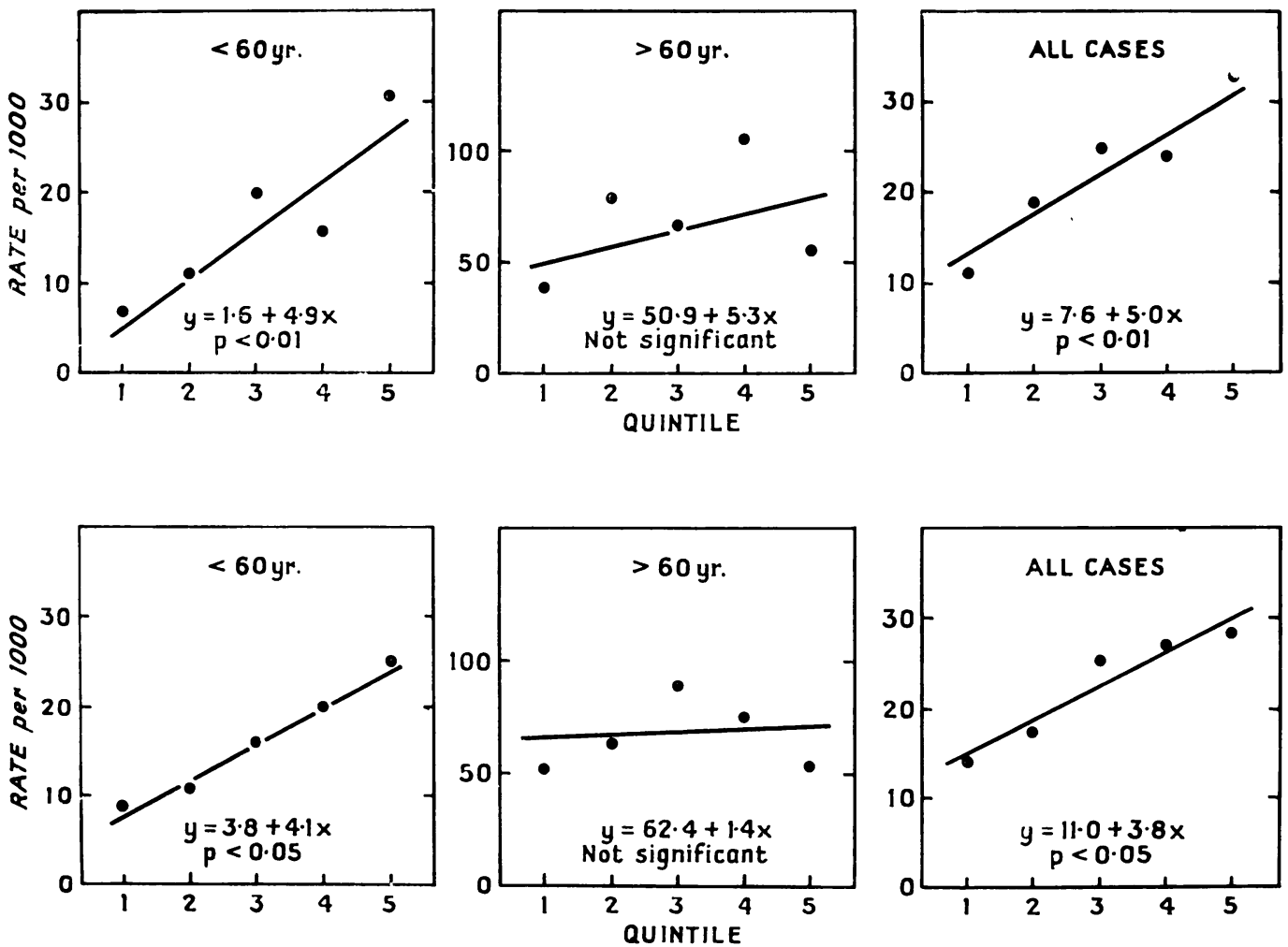

Fig. 2 Rate of occurrence of new episodes of ischaemic heart disease in relation to fasting plasma levels of triglyceride (top) and cholesterol (bottom). In order to eliminate the influence of age on the plasma lipid levels the 3168 men were grouped into decades. Within each decade the material was divided into quintiles for plasma cholesterol and triglyceride levels; quintile 1 consisted of individuals having the lowest $20 \%$ of the values, quintile 2 the following $20 \%$ etc. The three main age groups-under 60 years, 60 or above, and all ages-were then formed by adding the persons in each quintile from the appropriate decades. This procedure ensured that each quintile included subjects of varying ages and that the age dependence of the numerical variables had been taken into account (data from the Stockholm prospective study, Carlson and Böttiger, 1972. Figure reproduced by kind permission of the Editor and Publishers of Lancet, London).

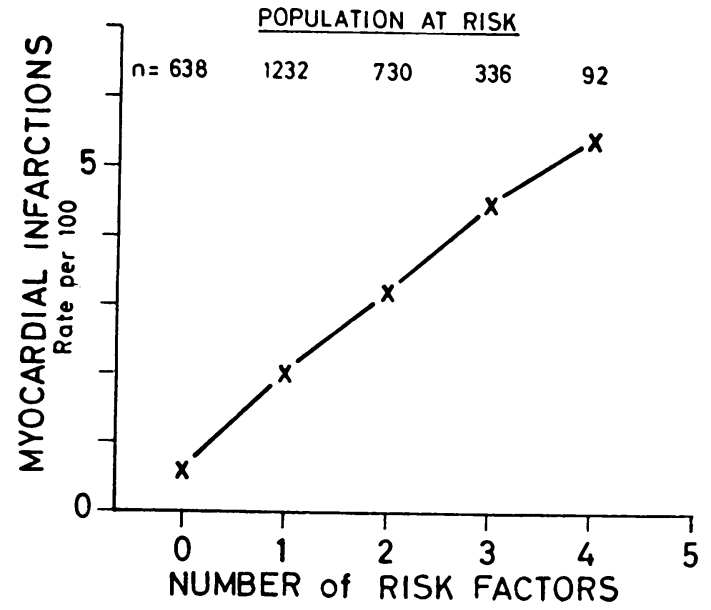

Fig. 3 Incidence of ischaemic heart disease in relation to the number of risk factors present. The risk factors were elevated plasma triglyceride, elevated plasma cholesterol, elevated blood pressure, smoking, and high ESR (data from the Stockholm prospective study). 
examined for signs of so-called subclinical atherosclerosis (Carlson, Ekelund, Eklund, B., and Olsson, A. G., not yet published). The frequency of the ischaemic ECG produced by exercise is shown in table IV. In the control there is an increase in the frequency of the ischaemic ECG on exercise with age, as expected, but there is a much greater increase with age in all three different groups of hyperlipidaemia, especially in the type IIB. This type with combined hyperlipidaemia thus once again emerges as the most malignant with regard to development of atherosclerotic diseases. Similarly, when the amplitude of the pulse wave of the big toe was determined as an indication of disease of the major arteries, once again those with type IIB were found to be significantly worse than the controls.

These three studies, one retrospective, one prospective, and one that we call 'interspective', all show that there is a close association between the different forms of hyperlipidaemia and clinical and subclinical ischaemic vascular disease.

Finally I should like to consider some results of quantitative lipoprotein analysis made with the preparative ultracentrifuge in a retrospective study of survivors of myocardial infarction and of subjects with peripheral vascular disease. The triglyceride and cholesterol data in men aged 35-55 years are presented in table V. It is seen that there is elevation of triglycerides in the very-low-density lipoprotein
(VLDL) fraction and in the low-density lipoprotein (LDL) fraction; the elevation of triglycerides in the LDL fraction has not been stressed previously. Cholesterol is significantly elevated in the VLDL and to a lesser extent in the LDL. It is worth noting that there is a consistent decrease in the high-density lipoprotein (HDL) fraction and that females, who have a lower incidence of myocardial infarction, have much higher HDL cholesterol levels than men (See page 32). Subjects over 55 years of age show a similar pattern (table VI), ie, elevation of VLDL and LDL triglycerides, here considerably greater in the myocardial infarction subjects than in those with peripheral atherosclerosis, and a decrease in HDL cholesterol.

The distribution of the different types of hyperlipoproteinaemia in these subjects is shown in figure 4. As expected most of the controls have a normal lipoprotein pattern, as do many of the patients. The most frequent abnormality is type IV hyperlipidaemia present in about $50 \%$ of the infarcts and $30 \%$ of those with peripheral vascular disease, followed by type II A and type II B.

The frequency of the sinking pre- $\beta$-lipoprotein discussed by Dr K. Carlson was $21 \%$ in control subjects in the main population consisting of 150 males of 50 years of age, and $22 \%$ in the other control sample of 60 males aged 35 to 70 referred to in tables V and VI. In the 54 cases of myocardial

\begin{tabular}{|c|c|c|c|c|}
\hline Age (years) & $\begin{array}{l}\text { Controls } \\
(\text { mean TG }=1 \cdot 12) \\
(\text { mean Chol }=239)\end{array}$ & $\begin{array}{l}\text { Type IIA } \\
(\text { mean TG }=1.68) \\
(\text { mean Chol }=389)\end{array}$ & $\begin{array}{l}\text { Type IV } \\
(\text { mean } T G=4.99) \\
(\text { mean Chol }=276)\end{array}$ & $\begin{array}{l}\text { Type } I I B \\
(\text { mean } T G=3.25) \\
(\text { mean Chol }=363)\end{array}$ \\
\hline $\begin{array}{l}<40 \\
41-50 \\
51-60 \\
>60\end{array}$ & $\begin{array}{r}0 \%(14) \\
17 \%(18) \\
14 \%(21) \\
29 \%(17)\end{array}$ & $\begin{array}{l}20 \%(5) \\
33 \%(9) \\
67 \%(22)^{4} \\
75 \%(8)^{2}\end{array}$ & $\begin{array}{c}0 \%(6) \\
21 \%(28) \\
42 \%(31)^{2} \\
67 \%(12)^{2}\end{array}$ & $\begin{array}{l}33 \%(3) \\
75 \%(8)^{3} \\
83 \%(6)^{4} \\
75 \%(8)^{2}\end{array}$ \\
\hline
\end{tabular}

Table IV Percentage of healthy, hyperlipidaemic subjects with an ischaemic ECG after exercise classified according to age and Fredrickson type of hyperlipidaemia ${ }^{1}$

${ }^{1}$ The numbers in parentheses indicate the total number of patients in the group.

$\mathrm{TG}=$ plasma triglyceride $(\mathrm{mmol} / \mathrm{l}), \mathrm{Chol}=$ plasma cholesterol $(\mathrm{mg} / 100 \mathrm{ml}),{ }^{2} 0.05>\mathbf{P}>0.01,{ }^{3} 0.01>\mathbf{P}>0.001,{ }^{4} \mathbf{P}<0.001$, compared with $\mathrm{the}$ corresponding control values.

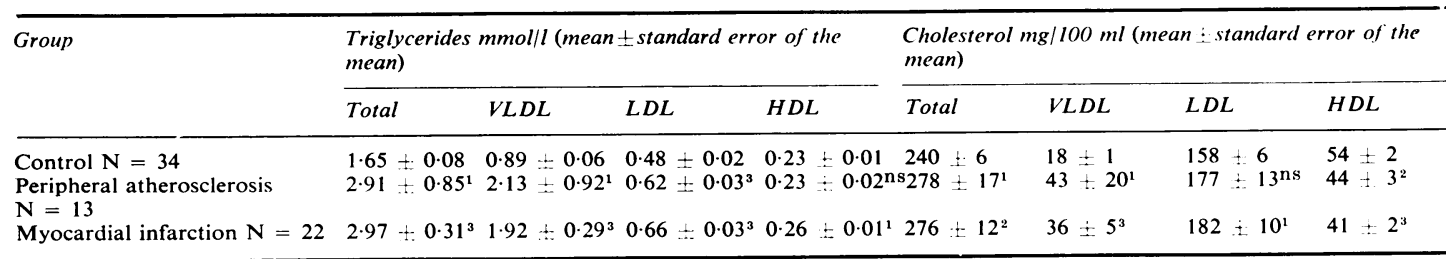

Table V Distribution of plasma triglyceride and cholesterol in the lipoprotein fractions of males aged 30-55 years with myocardial infarction or peripheral atherosclerosis from a study in progress in Uppsala

$\mathrm{N}=$ number of subjects

ns $=$ not significant, ${ }^{1} 0.05>P>0.01,{ }^{2} 0.01>P>0.001,{ }^{3} \mathrm{P}<0.001$ when compared with the corresponding control values. 


\begin{tabular}{|c|c|c|c|c|c|c|c|c|}
\hline \multirow[t]{2}{*}{ Group } & \multicolumn{4}{|c|}{$\begin{array}{l}\text { Triglycerides mmol/l (mean } \pm \text { standard error of the } \\
\text { mean) }\end{array}$} & \multicolumn{4}{|c|}{$\begin{array}{l}\text { Cholesterol }(\mathrm{mg} / 100 \mathrm{ml})(\text { mean } \pm \text { standard error of the } \\
\text { mean) }\end{array}$} \\
\hline & Total & $V L D L$ & $L D L$ & $H D L$ & Total & $V L D L$ & $L D L$ & $H D L$ \\
\hline $\begin{array}{l}\text { Control } N=26 \\
\text { Peripheral atherosclerosis } \\
N=37 \\
\text { Myocardial infarction } N=32\end{array}$ & $\begin{array}{l}1.63 \pm 0.09 \\
2 \cdot 11 \pm 0.13^{2} \\
3.22 \pm 0.35^{3}\end{array}$ & $\begin{array}{l}0.77 \pm 0.07 \\
1.24 \pm 0.11^{2} \\
2 \cdot 14 \pm 0.31^{3}\end{array}$ & $\begin{array}{l}0.55 \pm 0.03 \\
0.59 \pm 0.02^{\mathrm{ns}} \\
0.67 \pm 0.03^{3}\end{array}$ & $\begin{array}{l}0.25 \pm 0.01 \\
80.24 \pm 0.01^{\mathrm{n}} \\
0.28 \pm 0.01^{\mathrm{n}}\end{array}$ & $\begin{array}{l}250 \pm 8 \\
8263 \pm 8^{\text {ns }} \\
8301 \pm 9^{3}\end{array}$ & $\begin{array}{l}16 \pm 2 \\
25 \pm 3^{1} \\
49 \pm 9^{2}\end{array}$ & $\begin{array}{l}168 \pm 6 \\
179 \pm 7^{\mathrm{ns}} \\
149 \pm 9^{1}\end{array}$ & $\begin{array}{l}54 \pm 3 \\
45 \pm 2^{2} \\
46 \pm 3^{1}\end{array}$ \\
\hline
\end{tabular}

Table VI Distribution of plasma triglycerides and cholesterol in the lipoprotein fractions of males aged 56-72 years with myocardial infarction or peripheral atherosclerosis from a study in progress in Uppsala

$\mathbf{N}=$ number of subjects

$\mathrm{ns}=$ not significant, ${ }^{1} 0.05>\mathrm{P}>0.01,{ }^{2} 0.01>\mathrm{P}>0.001,{ }^{3} \mathrm{P}<0.001$ when compared with the corresponding control values.

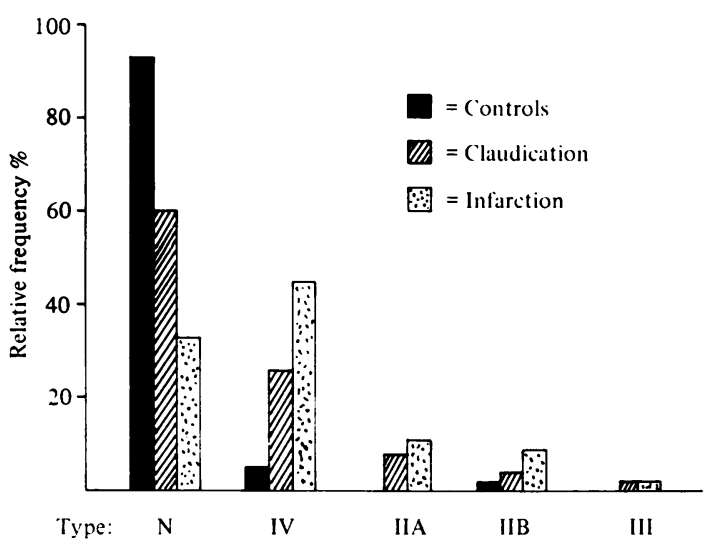

Fig. 4 Frequency of different types of hyperlipidaemia, as determined by quantitative lipoprotein analysis, in controls and subjects with myocardial infarction or peripheral atherosclerosis. $N=$ normal. infarction in the latter tables the incidence was $36 \%$ and in peripheral vascular disease it was as high as $47 \%$. The significance of this is not clear.

In summary, then, $I$ think it is true to say that there is a close association between the development of ischaemic vascular disease and different types of hyperlipidaemia. It is thus important for us to try to understand to what extent this association is causative. It is also important to study in man possible mechanisms which may cause the various types of hyperlipidaemia.

References

Carlson, L. A. (1960a). Serum lipids in normal men. Acta med. Scand., 167, 377-397.

Carlson, L. A. (1960b). Serum lipids in men with myocardial infarction. Acta med. scand., 167, 399-413.

Carlson, L. A., and Böttiger, L. E. (1972). Ischaemic heart-disease in relation to fasting values of plasma triglycerides and cholesterol. Lancet, 1, 865-868.

World Health Organization Memorandum (1970). The classification of hyperlipidaemias and hyperlipoproteinaemias. (By J. L. Beaumont et al) Bull. Wld Hlth Org., 43, 891-915. 